\title{
The Challenges of Undertaking Research into Participation in Modern Warfare: A Pragmatic Approach
}

\author{
Deidre Wild ${ }^{1 *}$ and Emmie Fulton ${ }^{2}$ \\ ${ }^{1}$ Faculty of Health and Life Sciences, Senior Research Fellow (Hon), University of Coventry, UK \\ ${ }^{2}$ Lecturer in Psychology, Behavioural Interventions Research, Coventry University, UK
}

Submission: March 13, 2019; Published: May 16, 2019

*Corresponding author: Deidre Wild, Faculty of Health and Life Sciences, Senior Research Fellow (Hon), University of Coventry, Coventry, CV1 5FB, UK

Abstract

This article focusses upon the theoretical and practical challenges arising from undertaking a research study into British non-Regular Services health professional troops' health and social well-being before and following participation in the Gulf War (1991). Its purpose is to describe the established and relatively new (in 1991) research theory that was considered for the overall design of the study. Research into spontaneous events such as war, by definition normally takes place where the inquiry happens and with those involved interacting within it. In this case, because of security, lack of permissions and distance it was not possible to fully meet this definition and what was planned was quickly changed to what was possible. In doing so, consideration was given to the appropriateness of qualitative and quantitative paradigm theories before embracing the pragmatic mixed methods that were eventually adopted. The preparations for this research and the theoretical decisionmaking that underpinned them formed a firm foundation in establishing an overall robustness for the study's methodology and findings.

Keywords: Research theory; Gulf War; Paradigms; Pragmatism

\section{Introduction to The Study}

The study comprised a postal survey with 3 questionnaire rounds, each six months apart and beginning with the first issued some four months after the GW veterans returned home. The main research objectives, established from a pilot study with 7 health professional non regular services veterans, were to monitor their health status, relationships and social support across a trajectory comprising pre-war preparations, during hostilities, in the first six months post war (retrospective data) and in two aftermath phases of 7-12 months and the 13 to 18 months after the end of the Gulf War (GW) (prospective data). The data collected were both qualitative and quantitative. By today's standards published British research into past warfare, conducted during or even a short time after hostilities was sparse at the time of the GW and was usually authored by those from medical or surgical disciplines with a focus upon the combatant and the physical injuries sustained. Few authors acknowledged the role of theory underpinning their war-related research and the reporting of what was and what was not possible methodologically was often overlooked.

In contrast, the early conduct of the present study caused some discomfort to the researcher as it initially evolved as a paper exercise to seek funding for a study without the comfort of knowing when it would start or finish. Not until the pilot study was conducted in the form of a small scoping exercise with 7 veterans shortly after their return from the Gulf (and further influenced by handful of related US and UK media reports on the war) was some real understanding of the issues arising from participation in the GW established and with this, the aims for the study became sufficiently clear to be articulated. The two central aims of this research was to explore the perceptions of a group of British non-combatant Reserve and Voluntary Services (VS) health professionals concerning their experience of participation in the Gulf War (GW) and to record changes in their health and social wellbeing from before to 18 months after the war's end. One further aim was to give them a collective voice. These are important for the following reasons:

i. The GW of 1990-91 remains a watershed in modern warfare as the only multi-national war in which troops were prepared for a biological and/or a chemical weaponry threat. Thus, documenting the reactions of those involved with casualty care could have implications for similar future warfare. 
ii. A 'voice' for this particular British veteran group has rarely been the focus of past British war-related research.

iii. Longitudinal changes in their health and social wellbeing have seldom been documented using an in-depth rigorous analytical approach for this group.

iv. Opportunity to study participation in a war in its entirety is infrequent yet important as 'a history in the making'.

\section{The Early Challenges to The Study's Development}

Wolcott [1] has likening the orderly development of a research study to the use of the assembly instructions for a wheelbarrow and suggests the need to: '.... make sure all parts are properly in place before tightening.'
(Wolcott, 1990) However, applying such logic to the early development of this war-related study was tortuous because it was subject to three specific challenges, as given in (Table 1). The first challenge, not in the control of the researcher, was related to the unpredictability of the unfolding history of the GW. For, late in 1990 (when preparation for the study commenced) not knowing when the land war would start or end and with what outcome also meant not knowing when troops would return home to the United Kingdom and be available to be approached as potential sample participants. An added pressure was that despite logistical uncertainties, the over-riding aim had to be to collect data as soon as possible from the research participants to minimise their recall error after their return home to their civilian lives in the first weeks of March 1991[2,3].

Table 1: Early challenges to the study's development.

\begin{tabular}{|c|}
\hline 1. Logistical Uncertainty \\
\hline The unpredictability of when the land offensive would start and finish. \\
When troops would return to the UK after the war's end. \\
\hline The veterans needed to be contacted as soon as possible after their return to minimise recall error. \\
\hline 2. Finding an Appropriate Theoretical Framework \\
\hline $\begin{array}{c}\text { Finding a research strategy for a life-changing event such as participation in warfare had few research precedents and no subscription to any one } \\
\text { theoretical paradigm. }\end{array}$ \\
\hline 3. Establishing Relevance for the Gw From A Review of the Literature \\
\hline The review of historical research literature of past UK wars revealed the under-research of complex bio-psychosocial aspects of participation in \\
warfare.
\end{tabular}

The second challenge lay in the difficulty in deciding what kind of research was to be undertaken with implications for the sample selection, methods and analysis. However, as this war was unique, the inquiry could only grow with the imparted knowledge of those who were there. Thus, the Pilot Study was hugely instrumental in revealing the need for a holistic biopsychosocial research approach $[4,5]$ to be given prominence in the study. Finally, attention in drawn to the importance of the role of literature, not just at the beginning of the study with an update at the end, as is often the case but as a regular accompaniment to the ongoing analysis. In this way each part of the study was informed by the preceding analysis.

\section{Theoretical Considerations to Make Sense of What Was Workable and What Was Not}

Recourse to research theory began with consideration of the two main paradigms or 'world views' [6] that have been perceived by some authors as being of greater importance than method [7]. These are often considered with logical positivist science at one end of a spectrum and with social sciences at the other. In short, positivist science has an epistemology from which its purists seek to produce objective value-free knowledge. Through the setting of hypotheses and their testing by experimentation and replication, cause and effect can be established, prediction enabled, and legitimate generalization can be made from the results [8]. The underlying assumptions, often under debate, are that through reduction there is one reality and a fact are both measurable and true [9-11].

In contrast, social science seeks to enable understanding and explanation of a human problem through the generation of hypotheses from a depth and breadth of related information $[12,13]$. The information may be variable orientated with large samples using inferential statistics or case orientated using a small number of cases using narrative analysis techniques [14]. Its stance is subjective and value-bound within a natural [15-17] or 'Real World' setting [18]. Transferable findings rather than generalization can be an aim. Its underlying philosophy subscribes to multiple realities that are constantly changing, thus cause and effect are believed to be inseparable [17], although some authors have suggested that causality can be inferred [19].

Commonly, quantitative research (implying a numeric form) has been more associated with logical positivism and qualitative research (implying a literary form) with the social sciences. The above differences between these paradigms resulted in a polarization of their respective theories and theorists in what has been described as the 'paradigm wars' [11-21]. From these theoretical clashes, a third theory has come into prominence; pragmatism. This is a set of philosophical ideas articulated first by the philosopher, Charles Sanders Pierce in the late $19^{\text {th }}$ 
century. Its contemporary form draws upon the concept of 'what works' and by valuing both objective and subjective knowledge, it offers choices about what to research and how to go about it, as given in the following description by Cherry Holmes [22]: 'For pragmatists, values and visions of human action and interaction precede a search for descriptions, theories, explanations, and narratives. Pragmatic choices about what to research and how to go about it are conditioned by where we want to go in the broadest of senses. Values, aesthetics, politics, and social and normative preferences are integral to pragmatic research, its interpretation and utilization.'

(Cherryholmes, 1992)Cherryholmes (1992) also suggests that by using what is known about the actions and interactions of the research participants and by anticipating the consequences of these, the researcher can choose the method(s) appropriate to elicit responses as to the what and how questions of an inquiry. Rossman and Wilson [23] were early proponents of pragmatism as an overarching philosophy for mixed methods research (MMR). In this, they provided four purposes for MMR given as corroboration, elaboration, development and initiation, as an alternative to the purists' view of the above paradigm-led research approaches. Although in its infancy in 1991, MMR was not without precedent and had already been used in: applied science [24]; in policy research [25]; in case study research [26] and in social science research [22-27]. However, as pragmatism has neither a requirement to define the 'mix' of methods nor their paradigms of origin, several authors have recommended the need for theoretical justification of both qualitative and quantitative methods when using MMR [28,29].

They suggest that different philosophical paradigms and methods are compatible because they are not inherently linked and as these authors perceive it, quantitative procedures are not always objective, and qualitative procedures are not always subjective. In contrast, other authors $[30,31]$ have questioned the feasibility of combining different methods on the basis of the incompatibility of paradigms. Both Ragin [14] and Reichardt and Cook [28] have cautioned that although quantitative and qualitative methodologies are complementary and there are advantages to combining them, there remains the risk of irreconcilable results.

In an attempt to steer theory away from the debate as to if or how MMR and pragmatism fits within an existing paradigm or can stand alone, Bryman [27] has focused upon the "how, when and why methods could be combined". Finally, whereas other authors[23,32] have sought to provide conceptual frameworks for the design and analysis phases of MMR, Krantz [33] has suggested that the relative merits of quantitative and qualitative approaches could be better understood by simply observing what researchers actually do to produce their research outputs.

\section{Theory and Reality}

The initial intention of securing matched controls for the study's participant GW veterans, in line with a randomised control trial design (believed at that time by the researcher to be the pinnacle of merit) was abandoned early in the research preparations due to an understandable lack of military support to permit and facilitate access at home and in the Gulf to serving military personnel. Fortunately, the researcher gained opportunistic access to an initial sample ( $n=57)$ of non-Regular Territorial Army and Reservist participants newly returned together from the GW. These recruits were invited to contact other GW veterans who had held similar roles to their own in the GW. This more purposive intervention provided a further 38 veterans in a similar range of health occupations in the GW to those held by the initial cohort of recruits raising the total to 95 participants. It is recognised that this approach could have introduced bias but realistically, such limitation is often unavoidable in research into spontaneous events such as man-made and natural disasters in which the researcher has little control. In the case of wars, there are the additional constraints around researcher and participant safety and operational security as further limitations upon the research's design, strategy and conduct. In recognising the difficulty of research that is of nature too complex to be compartmentalised, Robson[18] aptly describes an alternative 'Real World' approach that: '...[involves] people in a 'real life' situation to draw attention to some of the issues and complexities involved; and to generate a degree of informed enthusiasm for a particularly challenging and important area of work (p2). [It seeks] ....to say something sensible about a complex, and relatively poorly controlled Bryman A (1992) Quantity and Quality in Social Research. (2nd Ed), London and New York: Routledge, 45-71, 127156. This 'common sense' approach does not diminish the need for theory but rather than fit the study to a theory at outset, it sought theory to fit the study as its challenges unfolded. However, be warned, in exercising this freedom (as in the present study) a large amount of related qualitative and quantitative data is likely to be collected and ongoing analysis will raise new questions that may need to be investigated to meet the study's purpose. Furthermore, the open mind required for the pragmatic stance integral to Real World Research did not diminish consideration of the theory pertaining to each of the above paradigms but required clarity as to why neither of them was an exact 'fit'.

\section{Creating A Visual Framework to Support the Com- plex Inquiry}

From the early post GW literature, a chronological context for the GW emerged as a series of time-phases of different experiences [34]. This phased trajectory enables war to be studied from phase to phase as a life-changing event. As shown in (Figure 1), the trajectory model for this study comprises two active military service phases: phase 1. pre-deployment and phase 2. deployment; a phase of reunion and re-entry to civilian life after the end of the war [phase 3] followed by two aftermath phases (phase 4). Superimposed upon these phases in the present study was the additional qualitative concept of the participant as a civilian before entry to the military at pre-deployment [phase 1]; becoming a soldier in deployment [phase 2], the return home as 
a civilian war veteran [phase 3] and finally the experience of the war's longer term aftermath [35] [phases 3 and 4]. The advantage of this simple descriptive model lies in its ability to visually reflect qualitatively the complex aspects of inquiry within individual time phases as well as quantitatively observing changes to health, relationships and social support across the time phases.

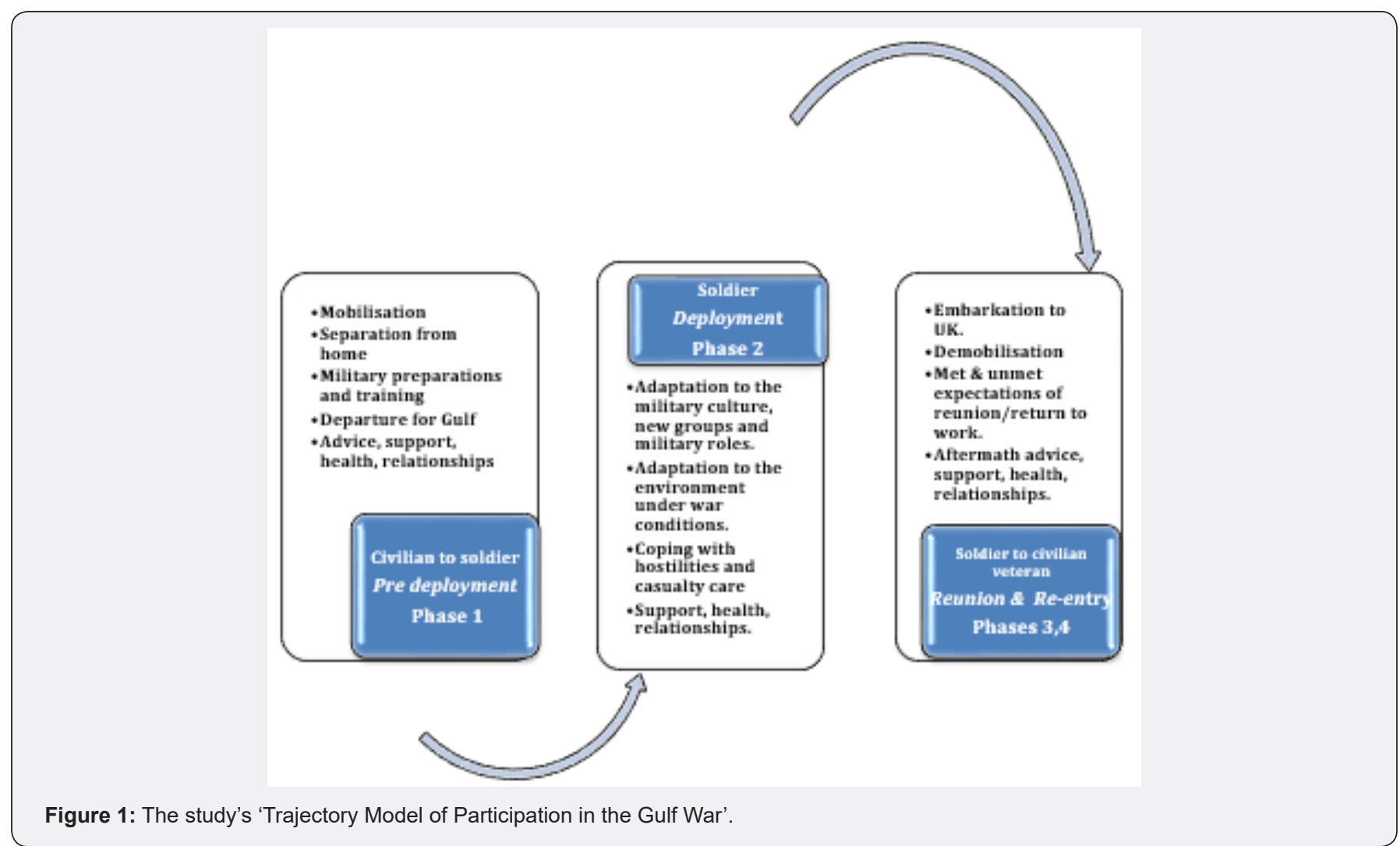

\section{Conclusion}

This article has described the theory considered during the development and conduct of a study of non-Regular Services health professionals in the GW. The approach adopted was one of pragmatism towards the study's early challenges in seeking an appropriate design and boundaries for the research. In 1991 the use of MMR was a relative newcomer to paradigmatic research theory and became a natural partner to the pragmatic approach of Real-World Research adopted as a 'best fit'. The timephased model, representing both qualitative and quantitative approaches, helped to visually clarify the boundaries, the type of data collected and to support their analyses. Flexibility was needed to take account of and simplify the complexity of the relationships within and between the data strands of the inquiry, i.e. health, social relationships and support. Literature reviewing was not undertaken as a single informative activity but integral to the conduct of the research throughout the life of the study. Undoubtedly this approach is time-consuming, but it is believed that the understanding gained from describing such a complex life event more than justifies the effort needed in its production.

\section{References}

1. Wolcott HF (1990) Writing up qualitative research. Newbury Park, CA: Sage, 47.
2. Wessley S, Unwin C, Hotopf M, Hull L, Ismail K, et al. (2003) Stability of recall of military hazards over time: evidence from the Persian of 1991. British Journal of Psychiatry 183(4): 314-322.

3. Parker RM (1993) Threats to the validity of research. Rehabilitation Counseling Bulletin 36(3):131-138.

4. Engel GL (1977) The need for a new medical model: a challenge for biomedicine. Science 196 (4286): 129-136.

5. Engel GL (1980) The clinical application of the Biopsychosocial Model. American Journal of Psychiatry 137(5): 535-544.

6. Patton MQ (1978) Utilisation-focused Evaluation. Beverly Hills, CA: Sage Publications, pp. 203.

7. Guba EG, Lincoln YS (1994) Competing paradigms in qualitative research. In: Denzin, N. K. and Lincoln, Y. S. (eds.) Handbook of Qualitative Research. Thousand Oaks, CA: Sage, 105-117.

8. Schrag F (1992) In defence of positive research paradigms. Educational Research 21(5): 5-8.

9. Popper KR (1959) The Open Society and Its Enemies. London: Routledge. Caldwell, B. (1980) Positivist philosophy of science and the methodology of economics. Journal of Economic Issues 14(1): 3-76.

10. Nagel T (1986) The View from Nowhere. New York. Oxford University Press inc., pp.1-7. Lincoln YS \& Guba EG (1985) Naturalistic Inquiry. Edition Newbury Park and London: Sage.

11. Caldwell B (1980) Positivist philosophy of science and the methodology of economics. Journal of Economic Issues 14(1): 53-76. 
12. Bryman A (2006) Integrating quantitative and qualitative research: how is it done? Qualitative Research 6(1): 97-113.

13. Lincoln YS, Guba EG (1985) Naturalistic Inquiry. Edition Newbury Park and London: Sage.

14. Ragin C (1987) The Comparative Method: Moving Beyond Qualitative and Quantitative Strategies. Berkeley, CA: University of California Press, 69-78.

15. Smith JK (1983) Quantitative versus qualitative research: An attempt to clarify this issue. Education Researcher 12(3): 6-13.

16. Guba EG, Lincoln YS (1989) Fourth generation evaluation. London: Sage.

17. Guba EG (1990) The Paradigm Dialogue. London. Sage 10-17.

18. Robson C (1993) Real World Research. A Resource for Social Scientists and Practitioner-researchers. Oxford: Blackwell Publishers.

19. Little D (1991) Varieties of social explanation: An introduction to the philosophy of social science. Edition Boulder, CO: Westview 24-25

20. Gage NL (1989) The paradigm wars and their aftermath: A "historical" sketch of research on teaching since 1989. Educational Researcher 18(7): 4-10.

21. Hammersley M (1989) The dilemma of qualitative method: Herbert Blumer and the Chicago tradition. London: Routledge.

22. Cherryholmes CH (1992) Notes on Pragmatism and Scientific Realism. Educational Researcher 21(6): 13-17.

23. Rossman GB, Wilson BL (1985) Numbers and words: Combining quantitative and qualitative methods in a single large-scale evaluation study. Evaluation Review 9(5): 627-643.

24. Cook TD, Campbell DT (1979) Quasi-Experimentation: Design and Analysis Issues for Field Settings. Boston, MA. Houghton Mifflin Company.

25. Hakim C (1987) Research Design. Strategies and Choices in the Design of Social Research. London: Allen and Unwin.
26. Yin RK. (1989) Case study research: Design and methods. Applied Social Research Series 5. London: Sage, 74.

27. Bryman A (1992) Quantity and Quality in Social Research. (2nd Ed), London and New York: Routledge 45-71, 127-156.

28. Reichardt CS, Cook TD (1979) Beyond Qualitative Versus Quantitative Methods in Evaluation Research. Beverley Hills, California. Sage 7-32.

29. Kidder LH, Fine M (1987) Qualitative and quantitative methods: When stories converge. In: Mark MM, Shotland RL (eds.) Multiple methods in program evaluation: New directions for program evaluation. San Francisco: Jossey-Bass. 57-75.

30. Buchanan DR. (1992) An uneasy alliance: Combining qualitative and quantitative research. Health Education Quarterly. 19(1), 117-35.

31. Guba EG, Lincoln YS. (1994) Competing paradigms in qualitative research. In: Denzin N K \& Lincoln YS (eds.) Handbook of Qualitative Research. Thousand Oaks, CA: Sage. 105-117.

32. Greene JC, Caracelli VJ (1997) Defining and describing the paradigm issue in mixed-method evaluation. In: Greene JC, Caracelli VJ. (eds.) Advances in mixed method evaluation: The challenges and benefits of integrating diverse paradigms. Edition San Francisco: Jossey-Bass. $5-17$.

33. Krantz DL (1995) Sustaining vs. resolving the quantitative-qualitative debate. Evaluation and Programme Planning 18(1): 89-96.

34. Norwood AE, Ursano RJ (1996) The Gulf War. In: Ursano RJ \& Norwood AE. (eds) The emotional aftermath of the Persian Gulf War. Veterans, families, communities and nations. Washington DC: American Psychiatric Press Inc., USA, p. 3-21.

35. Dunning CM. (1996) From citizen to soldier: Mobilisation of Reservists. In: Ursano RJ, Norwood AE. (eds.) Emotional aftermath of the Persian Gulf War. Veterans, families, communities and nations. Washington DC: American Psychiatric Press, USA, pp. 197-226.

\section{Your next submission with Juniper Publishers} will reach you the below assets

- Quality Editorial service

- Swift Peer Review

- Reprints availability

- E-prints Service

- Manuscript Podcast for convenient understanding

- Global attainment for your research

- Manuscript accessibility in different formats

( Pdf, E-pub, Full Text, Audio)

- Unceasing customer service

Track the below URL for one-step submission https://juniperpublishers.com/online-submission.php 